Programa de Pós-graduação em Letras/Estudos Literários da Unimontes v.21, n.1, 2020. ISSN: 2179-6793

\title{
ENTREVISTA COM A ESCRITORA SURDA SHIRLEY VILHALVA
}

https://doi.org/10.46551/21796793202000010

Prof. Dr. Marcio Jean Fialho de Sousa Universidade Estadual de Montes Claros - UNIMONTES pcopmarciojean@gmail.com iD tttps://orcid.org/0000-0001-8512-574X

Shirley Vilhalva Universidade Federal do mato Grosso do Sul - UFMT shivi323@hotmail.com iD Ittps://orcid.org/0000-0002-8206-9401

Shirley Vilhalva, nascida em Campo Grande, estado de Mato Grosso do Sul, no ano de 1964, pedagoga, professora da Universidade Federal do mato Grosso do Sul - UFMS. Escritora e poeta Surda, tem contribuído com a Comunidade Surda a partir do desenvolvimento de diversos projetos de pesquisa e de divulgação da Cultura Surda. Estreia na Literatura com a publicação do livro Despertar do Silêncio, no ano de 2004, de cunho autobiográfico, suscita profundas reflexões acerca dos desafios e conquistas das pessoas surdas no Brasil, não deixando de proporcionar momentos de verdadeira fruição e deleite.

Em meio ao isolamento causado pela crise mundial causada pela pandemia do coronavírus, concedeu-me, gentilmente, esta entrevista, na qual discute aspectos da Literatura Surda e de seu particular processo criativo. A entrevista foi concedida no dia 24 de abril, dia em que se comemoram os 18 anos da lei 10.436 que reconheceu a Libras como segunda língua oficial do Brasil, sendo a primeira língua para a comunidade surda.

Prof. Dr. Marcio Jean Fialho de Sousa (MJFS): Como você se define como escritora surda?

Shirley Vilhalva (SV): Ser escritora surda é algo que não tinha pensado ou perguntado para meu âmago. Não consigo fazer uma definição exata, pois desde pequena escrevo diário e é desse diário que surge meus escritos. Quando sento para dar essa entrevista em escrito, me coloca em um túnel do tempo que me mostra que, como escritora surda, é mais fácil ser entendida por leitores surdos e ouvintes, pois alguns colegas cegos sentem dificuldades com a maneira direta de escrita e, como são auditivos, sempre me pedem para que seja passado pela 
revisão para que também eles possam entender. Bem, me defino como uma escritora que deseja mostrar uma cultura surda ao escrever, buscando transmitir uma mensagem e expanda e proponha uma reflexão critica.

MJFS: Quando se fala em Literatura Surda no Brasil o seu nome sempre fica em evidência, basta ler os livros e os diversos estudos que debatem sobre essa temática, como você contribui com a Literatura Surda?

SV: Para ser bem sincera, foi você quem me mostrou essa evidência. Eu ainda não havia associado que o que escrevo poderia fazer parte da Literatura Surda do Brasil, muito menos que eu tenha contribuído com a Literatura e a Cultura Surda. Mas, às vezes, fico no pensar se realmente eu poetiso ou faço literatura ou mesmo uma cultura surda. Vou colocar aqui algo que escrevi um ano atrás e vou ver se tem algo que representa a cultura surda:

\section{Centelha de Sinais}

Shirley Vilhalva

Você nasceu com a centelha de sinais.

Você nasceu com a centelha de Amor e da Paz!

Todos os seres nascem com a centelha de sinais.

Ela está la!

Está em seu interior.

No seu universo carregado de configuração de mãos

em movimentos órbitais.

Mesmo que em silêncio você ativa,

Ela se ativa em configuração de mãos de encontro

no ponto de articulação e se expande nos movimentos.

E dai você transforma os seus primeiros sinais...

Você ainda vai se imaginar construindo os sinais

da língua de sinais que fará suas mãos a bailar.

Sua criança renascerá nas expressões faciais e

Corporais e até mesmo nas não - manuais.

Ela está lá!

No seu interior a centelha de sinais que transbordará 
e, fará você sonhar em língua de sinais.

Shirley Vilhalva - Campo Grande - MS 27/03/2019

Nesse poema acima você pode ver que é algo natural falar dos ritmos imaginário que eu vivo, onde escrevo o que vivo e me comunico.

MJFS: Como você pensa o cenário da Literatura Surda atualmente no Brasil?

SV: Eu penso que a Literatura Surda, atualmente, está mais apresentada em vídeo do que em escrita. Os escritores e escritoras surdas estão surgindo lentamente. Hoje já podemos encontrar escritores surdos que pararam de escrever e passaram a emanar suas poesias e narrativas em língua de sinais ou nas linguagens visuais usando a arte visual em vídeo. Alguns artistas usam imagens que emanam um olhar para constituição literária e depois imagética para Arte Surda. Veja um exemplo:

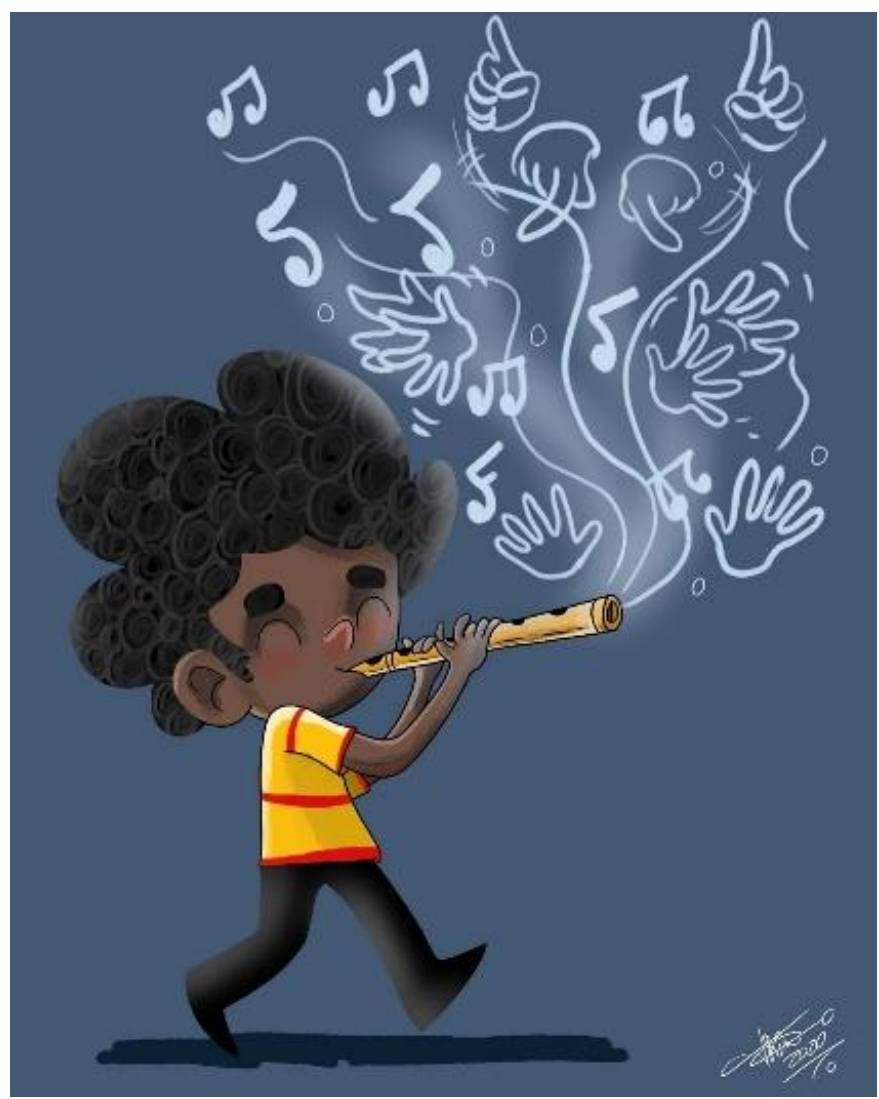

Autor TIKINHO, 2020.

(https://www.facebook.com/lucas.ramom.50)

Uma imagem cheia de poesia e música. Como escritora surda eu traduziria essas imagens mostrando que consta Configurações de Mãos e Sinais em ritmo, seria 
aproximadamente isso que anoto abaixo como uma leitura de impressão da Arte Surda do autor Tikinho:

Olá ...olá....

Olá ...olá....

A minha língua de sinais segue cantando.

Venha nessa... venha nessa aventura.

No som da maestria do bailar das mãos.

Venha nessa...

Olá ...olá....

Olá ...olá....

Já vem vindo o show.

Já vem vindo na minha língua de sinais!

Olá ...Olá...

Vem, vem, você também sinalizar!!!

Todo mundo pra língua de sinais!!!

MJFS: A Literatura Surda é escrita apenas por pessoas surdas?

SV: Não porque na comunidade surda tem os ouvintes culturalmente surdos, como os filhos de surdos conhecido como CODA; também os tradutores interpretes das língua de sinais. A literatura surda vem trazendo uma gama de informações principalmente pela Arte Surda. Também tem os ouvintes amigos que iniciam sua jornada no mundo da escrita onde tem cultura surda em seus escritos como a Anny Dantas, ouvinte que entrou na comunidade surda em 2017 e registrou na Biblioteca Nacional algumas de suas produções:

\section{Saudade com A}

Saudade escreve-se com S, mas no mundo visual ela está em A, porém o A não é a letra do alfabeto, porque no mundo das mãos é uma das configurações.

Embora para expressar saudade nem é necessário usar as mãos, já que nesse mundo ela pode ser expressa apenas com a expressão.

E assim é a saudade um sentimento deixado pela ausência ou pela falta de presença. 
Saudade daquele tempo, saudade das conversas, saudade da presença física, saudade do conhecimento e aprendizagens, saudade daqueles que me ensinaram a falar com as mãos e a ouvir com os olhos. (Anny Dantas, eterna aprendiz da Libras) 05-04-2020

\section{“Voz nas Mãos” Shirley Vilhalva}

Quem é essa mulher que eu fico a pensar... Ela tem voz nas mãos, nos lábios e no coração; fala-nos sem precisar das palavras, porque ela tem fala no olhar.

As mãos sinalizam com precisão: às vezes rapidamente e às vezes serenamente, mas sempre me propicia algum tipo de sentimento.

O olhar alcança o que os ouvidos não podem captar e eu não consigo deixar de admirá-la.

Ela é minha primeira referência nesse novo mundo; repleto de deslumbramentos, mulher de sorriso fácil, de abraço que fortalece.

É uma mulher de muitas virtudes e também alguns defeitos, mas qual ser humano está imune a eles? (Anny Dantas, eterna aprendiz da Libras) 22-11-2018

\section{Um olhar e suas histórias}

Observo o seu olhar a procura de respostas, pois em seu olhar encontrei dúvidas e inquietações.

Em suas palavras há beleza, motivação e certezas.

As mãos traz história e faz história, as mãos carregam as palavras e quantas palavras!

As mãos estão repletas de sabedoria,adquirida com o tempo dedicado aos livros, pesquisas, estudos e ensino.

Em suas mãos há força, lutas, desejos e sonhos.

As mãos usam as palavras e as palavras usam as mãos e nessa simetria seguem majestosas deixando sua marca e sua história.

Meus olhos tem o privilégio de gravar a história que há nessas mãos.

E assim sigo observando essas mãos de mente brilhante que não deixa os meus pensamentos. (Anny Dantas, eterna aprendiz de Libras) 10-09-2019. 
MJFS: No seu livro Despertar do Silêncio, publicado em 2004, pela editora Arara Azul, você apresenta as memórias sobre sua trajetória e seus desafios como surda. Você acha que a Literatura Surda tende a ser sempre textos memorialísticos? Por quê?

SV: No princípio eu acho que não tende e a se resumir em textos de memórias, o que acontece é que alguém te mostra como seria importante que as pessoas conhecessem a sua história e isso pode ajudar a pessoa entender o mundo visual sem preconceitos, mas como um novo despertar. O livro Despertar do Silêncio veio de um outro livro caseiro que tinha o nome Recortes de Uma Vida. Depois, a Editora Arara Azul, onde a diretora é mãe de surdo, entendeu a importância da escrita e se propôs publicar de modo gratuito, principalmente, para familiares de surdos. O livro registrou meus últimos momentos como Diretora de Escola de Surdos de Campo Grande - Mato Grosso do Sul, naquele momento, eu fui reconhecida como a primeira mulher surda brasileira e professora a assumir cargo de Diretora de uma escola pública de surdos por meio de concurso de seleção de diretores, pois, como sabemos, o primeiro diretor surdo foi E. Huet, um professor surdo francês. Como eu estava dizendo que além de recortar a trajetória, também deixei marcada em minha memória, isso foi uma forte motivação para as minhas próximas metas, com projetos inovadores que deixei registrado com as palavras que deixei na página 64. do livro Despertar do Silencio, em 31 de outubro de 2000, que transcrevo:

\section{"É irrefutável a importância que tem a Educação para o desenvolvimento social da nação.}

(Frase escrita por Therezinha de Alencar Selem durante a entrega da Medalha de Mulheres que marcaram o milênio passado, século XX. A quem eu tenho agradecimento especial pela escolha de meu nome e indicação como uma personalidade do século passado que fez diferença na Educação Especial do Estado de Mato Grosso do Sul)". 
MJFS: Você pensa em fazer nova edição do livro Despertar do Silêncio?

SV: A Editora Arara Azul já buscou projeto para publicação, mas até o momento não encontramos.

MJFS: Além do texto em prosa, você também escreve poesias. Pretende reunir suas poesias em uma antologia? Pode falar um pouco a respeito?

SV: Eu tenho alguns textos em prosas, poesias e estou sendo motivada a publicar, estou amadurecendo a ideia ainda, um de meus escritos vou colocar aqui para que possam apreciar:

\section{Não encontrei!}

Ao chegar do Morro da Gruta depois de uma cavalgada Pantaneira

Resolvi deitar na grama embaixo de um Flamboyan florido onde você ilustrava meu pensamento.

Eu já tinha andado em muitas páginas em busca de algo que pudesse exprimir emoções de meus sentimentos e em nenhuma encontrei...

A descrição do sabor de seus lábios que eu conheci.

A destreza de suas mãos deslizando sobre o meu vestido.

O ninhar de seu queixo em meu ombro enquanto tentava encaixar meu corpo ao seu.

Nenhuma linha que li contava a velocidade de seu sangue correndo em suas veias ao sentir acariciado em momentos ditosos.

Não havia também o que lembrasse dos beijos que a distância não permitiu sentir.

Encontrei mágicos dizeres, porém nem mesmo assim havia como comparar a volúpia de nossos momentos que entre energias surgiram.

Não encontrei nada que dissesse a cor de seus pensamentos e muito menos a referência dos meus.

Desejos se espalharam, assim resolvi escrever essas singelas palavras e pedir: "Lembre-se de momentos com Doce Pantaneira"

Escrito nos anos 90

Alguns escritos, parecem apaixonados, más descobri que entre as letras e 
os sentimenos há como produzir singeleza dos pessamentos humanos, bem como atrocidades. Cada um faz escolha do seu imaginários com as letras no papel.

Ao postar essa prosa, comecei a rir e vontade de corrigir o português mas senti tranquila ao não mexer, deixar assim original.

MJFS: Como é seu processo de escrita, você escreve esporadicamente ou existe certa regularidade?

SV: Eu escrevo todos os dias, pois atualmente estou fazendo o doutorado e mexendo melhor com a escrita livre e a acadêmica. Estou me desafiando agora a escrever sobre a Identidade Idioma Visual, em um olhar quântico no qual a referência é um conjunto de pessoas com eloquência pela língua de sinais, podendo ser surda ou ouvinte, que concebem de forma afirmativa os atributos culturais dessa língua visual, da cultura surda, da identidade surda, transcendendo a identidade linguística e trazendo a exterioridade de produtos que fazem uso das marcas linguísticas, como as configurações de mãos e demais elementos em sinais. Assim, promove-se o idioma que se vê de forma sublime e estabelece vínculos com as instituições e serviço específicos ao povo surdo. E, assim se segue...

MJFS: Qual é a importância da Literatura surda para a comunidade surda e para os ouvintes?

SV: É como adentrar em um espaço cibernético e encontrar a imensidão de algoritmos imagéticos e eles, em funcionamento, revelar o que existe em um escritor surdo.

MJFS: Você é uma surda oralizada, parece-me que existe certa resistência de alguns surdos em se oralizar ou até mesmo em aprender a língua portuguesa. Como você vê essa situação?

SV: Como surda falante e sinalizante, essa pergunta eu não sou muito apta a responder, pois nascem surdos em minha família há 70 anos. Sendo assim, não considero que exista resistência de alguns surdos em se oralizar ou até mesmo em aprender a língua portuguesa. Há algo mais. 
MJFS: Você poderia deixar algumas palavras aos que ainda não conhecem a Literatura Surda?

SV: Querido leitor, você que chegou até aqui, deve ter percebido quantas palavras você gostaria de mudar ou mesmo acrescentar pontos, vírgulas e outras coisinhas a mais que você ganhou sonoramente. Então para finalizar gostaria de convidar você a entrar no nosso mundo visual. É um mundo tão rico quanto o seu e, como escritora surda, quero deixar algo para você:

Nessa caminhada,

Um dia emos de nos encontrar.

Não sabemos exatamente onde, se será em um livro ou num tablet ou em um celular.

Você vai me ouvir com seus olhos e,

Por eles imaginar, e até que eu te levar a sonhar nas línguas de sinais.

Obrigada, Shirley Vilhalva!

Recebido em 24 de abril de 2020. Aprovado em: 04 de maio de 2020. 